\title{
Concomitant B Hairy Cell Leukemia and Mycosis Fungoides in an Elderly Man
}

\author{
Eric Wong ${ }^{a} \quad$ Muhammad N. Mahmood $^{b}$ Thomas G. Salopek ${ }^{a}$ \\ ${ }^{a}$ Division of Dermatology, Department of Medicine, University of Alberta, \\ Edmonton, $A B$, Canada; ${ }^{b}$ Department of Laboratory Medicine and Pathology, University of \\ Alberta, Edmonton, $A B$, Canada
}

\section{Keywords}

Hairy cell leukemia $\cdot$ Mycosis fungoides $\cdot$ Cutaneous T-cell lymphoma

\begin{abstract}
The development of both a T- and B-cell lymphoproliferative disorder in one patient is an unlikely coincidence due to the low prevalence of each malignancy. We report a 65-year-old man with a previously documented history of B hairy cell leukemia, who presented with a new-onset acneiform eruption of his scalp, face, trunk, back, and extremities. Routine pathology of the skin lesions with immunohistochemical stains and molecular studies were consistent with a folliculotropic mycosis fungoides. B hairy cell leukemia and mycosis fungoides occurring in the same patient seems to be a rare phenomenon with only 5 cases reported in the literature.

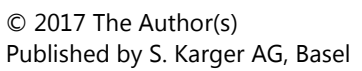

\section{Introduction}

Mycosis fungoides, the most common type of cutaneous T-cell lymphoma, can often be a difficult diagnosis that can have a protracted clinical course without definitive identification years after initial presentation. This disease accounts for about $50 \%$ of all primary cutaneous lymphomas [1]. B hairy cell leukemia is a chronic B-cell malignancy characteristically diagnosed by the presence of pancytopenia, splenomegaly, and "hairy cells" with a specific 
immunoprofile present in the blood, bone marrow, and other tissues [2]. This malignancy accounts for approximately $2 \%$ of all leukemias [2]. In general, mycosis fungoides and B hairy cell leukemia are both uncommon lymphoproliferative malignancies.

\section{Case Report}

A 65-year-old man was seen at the University Dermatology Clinic for a 9-month history of intensely pruritic red papules initially of the scalp and progressing to his face and rest of his body. The patient complained of generalized fatigue, severe pruritus, and night sweats causing an inability to maintain a job. He was previously treated empirically with oral antipruritic medications and topical corticosteroids with no improvement.

Past medical history was significant for B hairy cell leukemia, hypertension, sleep apnea, gout, gastroesophageal reflux disease, a left knee replacement for osteoarthritis, and a clear cell renal cell carcinoma requiring a partial nephrectomy. Further history revealed no family history of skin cancers or hematological malignancies.

A diagnosis of B hairy cell leukemia was made 3 years prior based on the presence of lymphocytosis (lymphocyte count of $9.5 \times 10^{9} / \mathrm{L}$ ) with corresponding flow cytometry (positive for CD19, CD20, CD22, CD25, CD103, CD11c, FMC-7, CD79b, and SigM/D) and enlarged spleen (19 cm in size). The B cells accounted for $72 \%$ of the gated lymphoid cells and were monoclonal ( $\lambda$-restricted). No coexpression of CD5 or CD10 was identified. The peripheral blood smear revealed a population of medium-sized lymphoid cells with monocytoid nuclei and moderate to abundant cytoplasm consistent with hairy cells. A bone marrow biopsy of the right iliac crest showed infiltration by small- to intermediate-sized lymphoid cells in a diffuse manner. These lymphoid cells had round nuclei with small nucleoli or clumped chromatin surrounded by empty spaces giving an appearance of a fried egg. Examination of the splenectomy specimen showed extensive infiltration of the splenic red pulp with the white pulp mostly depleted. On higher magnification, the nuclei of neoplastic cells were relatively vesicular and the nucleoli were often visible. These cells were positive for CD20 and BDA44 but negative for CD123 on immunohistochemistry. His hairy cell leukemia was treated with chemotherapy, specifically cladribine, and then rituximab (due to a poor response to the former), and a splenectomy with complete remission.

On examination, he had multiple erythematous papules and pustules, many of which appeared to be follicular-based with secondary crusted excoriations. The lesions were widely distributed on his scalp, face, trunk, back as well as the upper and lower extremities (Fig. 1a). There was a cluster of patches coalescing into plaques noted on the left upper back.

Biopsies of the scalp showed extensive solar elastosis of the papillary and reticular dermis with mild acanthosis and hyperkeratosis (mainly orthokeratosis with focal parakeratosis) overlying the epidermis. Pautrier microabscesses and epidermotropism were not noted. Dermal perifollicular infiltrates were predominantly formed by lymphocytes, which extended into the folliculosebaceous units with associated epithelial mucinosis. Eosinophils were noted within the infiltrate. Immunohistochemical stains were positive for CD2, CD3, and CD4 and negative for CD8 and CD20. Overall, these features were consistent with folliculotropic mycosis fungoides. Biopsies performed from the patches on the upper back disclosed mild to moderate superficial perivascular and patchy lichenoid infiltrate of lymphocytes (Fig. 1b). In foci, the lymphocytes showed epidermotropism and were aligned along the basal layer of the epidermis (Fig. 1c). Overall, the biopsies from the upper back area were consistent with patch-stage mycosis fungoides. 


\section{Case Reports in Dermatology}

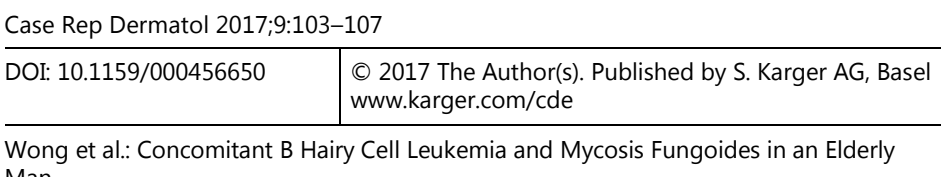

Man

T-cell gene rearrangement assays on the skin revealed a polyclonal pattern; however, $\mathrm{T}$ cell gene rearrangement studies on peripheral blood revealed monoclonality. Flow cytometry showed that lymphocytes accounted for $44 \%$ of the total events with only $5 \%$ of the cells being B cells. The B cells were monotypic $(\lambda)$ and immunophenotypic to the hairy cell leukemia variant, specifically CD103 and CD25 positive and CD5 negative. The T cells accounted for $77 \%$ of the total lymphoid cell population with a CD4:CD8 ratio of 1:2.5. The T cells had a loss of CD26 in a subset of CD4-positive cells, which was suggestive of Sézary cells.

Treatment with nbUVB phototherapy 3 times weekly to his entire body with clobetasol propionate spray occlusion to his scalp improved his symptoms and most of the lesions resolved within several months.

\section{Discussion}

A thorough review of the literature on PubMed, using the search terms ("mycosis fungoides" OR "cutaneous T-cell lymphoma") AND (leukemia OR leukaemia OR lymphoma OR "lymphoid malignancy" OR "Hodgkin's disease" OR "non-Hodgkin's disease" OR "multiple myeloma" OR "B-cell"), identified 68 cases of concomitant mycosis fungoides and a lymphoid malignancy [2, 4-27]. Narrowing the results, we were able to find 5 cases of hairy cell leukemia along with mycosis fungoides reported $[2,5]$. However, the possibility that both Tand B-cell malignancies occurring unrelated to one another in one patient is unlikely, as the incidence of each cutaneous and systemic neoplasm separately is very low $[4,6]$. Therefore, the development of cutaneous T-cell lymphoma and hairy cell leukemia is a very rare phenomenon.

A trend seen in various studies demonstrated that patients who develop primary cutaneous T-cell lymphoma are at an increased risk of developing a secondary malignancy [3-5, 28]. Amber et al. [28] confirmed this through examination of the Surveillance, Epidemiology, and End Results (SEER) database of the National Cancer Institute. Through evaluation of all cutaneous T-cell lymphoma cases between 1992 and 2011, there was an overall increased risk of secondary cancers, particularly within the first year of diagnosis [28]. Sidwell et al. [18] reported a patient with mycosis fungoides who subsequently developed Hodgkin disease, but analysis of cells from the skin and lymph nodes disproved the notion that these cancers were derived from a single cellular origin [18]. From studies performed by Vakeva et al. [3], they propose that these cancers may have a cancerogenic effect causing an increased risk of malignancies, in particular lymphomas. There is little to no evidence to support the reverse. Similarly there does not appear to be a common genetic mutation for hairy cell leukemia and mycosis fungoides.

Although no consensus has been agreed upon, some authors suggest that a genetic predisposition for lymphoproliferative disease, an underlying viral infection, or possible mutagenic effects of cytostatic drugs as potential causes for developing concurrent B- and T-cell cancers [4]. Barzilai et al. [4] believe that alterations in progenitor stem cells prior to differentiation or production of cytokines by a first neoplasm stimulating the development of a secondary tumor can cause the development of B- and T-cell malignancies seen in one patient.

Not only is the case exceedingly rare, it highlights the need to consider cutaneous T-cell lymphoma in patients with a nonspecific follicular eruption that is intensely pruritic disproportionate to the clinical findings and has failed to respond to conservative treatments. 


\section{Statement of Ethics}

The patient provided consent for publication.

\section{Disclosure Statement}

The authors have no conflict of interest to declare.

\section{Author Contributions}

All authors contributed equally to the paper.

\section{References}

1 Bolognia JL, Jorizzo JL, Schaffer JV: Dermatology, ed 3. Philadelphia, Elsevier, 2009.

2 Paolini R, Poletti A, Ramazzina E, et al: Co-existence of cutaneous T-cell lymphoma and B hairy cell leukemia. Am J Hematol 2000;64:197-202.

-3 Vakeva L, Pukkala E, Ranki A: Increased risk of secondary cancers in patients with primary cutaneous T cell lymphoma. J Invest Dermatol 2000;115:62-65.

-4 Barzilai A, Trau MD, Feinmesser M, et al: Mycosis fungoides associated with B-cell malignancies. Br J Dermatol 2006;155:379-386.

5 Hallermann C, Kaune MK, Tiemann M, et al: High frequency of primary cutaneous lymphomas associated with lymphoproliferative disorders of different lineage. Ann Hematol 2007;86:509-515.

6 Herro E, DiCaudo DJ, Davis MD, et al: Review of contemporaneous mycosis fungoides and B-cell malignancy at Mayo Clinic. J Am Acad Dermatol 2009;61:271-275.

7 Grange F, Avril MF, Esteve E, et al: Coexistent cutaneous T-cell lymphoma and B-cell malignancy. J Am Acad Dermatol 1994;31:724-731.

8 Sheibani K, Forman SJ, Winberg CD, et al: Coincidence of B-cell chronic lymphocytic leukemia and cutaneous T cell lymphoma (mycosis fungoides): immunologic characterization by monoclonal antibodies. Blood 1983;62:1176-1181.

9 Geerts ML, Hamers J, Schwarze EW, et al: Mycosis fungoides and lymphoplasmoctoid immunocytoma in the same patient: a case report. Cancer 1984;54:2294-2299.

$\checkmark 10$ Peterman A, Jerdan M, Staal S, et al: Evidence for HTLV-1 associated with mycosis fungoides and B-cell chronic lymphocytic leukemia. Arch Dermatol 1986;122:568-571.

11 Aberer W, Groh V, Bettelheim P, et al: T- and B-cell double lymphoma: immunologic characterization using monoclonal antibodies (in German). Hautarzt 1988;39:388-392.

12 Allue L, Domingo A, Moreno A, et al: Simultaneous occurrence of cutaneous T cell lymphoma after successful treatment of follicular B-cell lymphoma. J Am Acad Dermatol 1990;23:667-681.

13 Van der Akker TW, Van der Willigen AH, Van der Kwast TH, et al: Cutaneous T cell lymphoma after successful treatment of follicular B-cell lymphoma. Br J Dermatol 1990;123:266-267.

14 Harland CC, Whittaker SJ, Ng YL, et al: Coexistent cutaneous T cell lymphoma and B-cell chronic lymphocytic leukemia. Br J Dermatol 1992;127:519-523.

-15 Castanet J, Lacour JP, Taillan B, et al: Mycosis fongoide survenant au cours d'un lymphoma B. Ann Dermatol Venereol 1992;119:205-208.

16 Chan WC, Griem ML, Grozea PN, et al: Mycosis fungoides and Hodgkin's disease occurring in the same patient: report of three cases. Cancer 1979;44:1408-1413.

-17 Hull PR, Saxena A: Mycosis fungoides and chronic lymphocytic leukaemia-composite T-cell and B-cell lymphomas presenting in the skin. Br J Dermatol 2000;143:439-444.

18 Sidwell RU, McLaughlin JE, Jones A, et al: Hodgkin Lymphoma in a patient with mycosis fungoides: molecular evidence for separate cellular origins. Br J Dermatol 2003;148:810-812.

19 Metzman MS, Stevens SR, Griffiths CE, et al: A clinical and histologic mycosis fungoides simulant occurring as a T-cell infiltrate coexisting with B-cell leukemia cutis. J Am Acad Dermatol 1995;33:341345 . 


\section{Case Reports in Dermatology}

\begin{tabular}{l|l}
\hline Case Rep Dermatol 2017;9:103-107 \\
\hline DOI: 10.1159/000456650 & $\begin{array}{l}\text { ○ 2017 The Author(s). Published by S. Karger AG, Basel } \\
\text { www.karger.com/cde }\end{array}$ \\
\hline
\end{tabular}

Wong et al.: Concomitant B Hairy Cell Leukemia and Mycosis Fungoides in an Elderly Man

20 Marschalk M, Csomor J, Eros N: Coexistence of primary cutaneous anaplastic large cell lymphoma and mycosis fungoides in a patient with B-cell chronic lymphocytic leukaemia. Br J Dermatol 2007;157:1291-1293.

21 Geldenhuys L, Radhi J, Hull PR: Mycosis fungoides and cutaneous Hodgkin's disease in the same patient: a case report. J Cutan Pathol 1999;26:311-314.

-22 Lemchak DM, Akilov OE: Romidepsin controls chronic lymphocytic leukemia in a patient with mycosis fungoides. Hematol Rep 2016;8:6840.

23 Clement M, Bhakri H, Monk B, et al: Mycosis fungoides and Hodgkin's disease. J R Soc Med 1984;77:1037-1039.

24 MacCormac H: Mycosis fungoides treated by malaria, terminating in Hodgkin's disease. Br Med J 1941;2:645-646.

25 Brousset P, Lamant L, Viraben R, et al: Hodgkin's disease following mycosis fungoides: phenotypic and molecular evidence for different tumor cell clones. J Clin Pathol 1996;49:504-507.

26 Salameh F, Barzilai A, Baum S, et al: Mycosis fungoides and CD30+ cutaneous T-cell lymphoma simulating pyoderma gangrenosum in a patient with ulcerative colitis. J Dermatol Case Rep 2009;3:3033.

27 Habboush HW, Lucie NP, Mackie RM, et al: Follicular mucinosis, mycosis fungoides, and acute myeloid leukemia. J Clin Pathol 1990;43:347.

28 Amber KT, Bloom R, Nouri K: Second primary malignancies in CTCL patients from 1992 to 2011: A SEER-based, population-based study evaluating time from CTCL diagnosis, age, sex, stage, and CD30+ subtype. Am J Clin Dermatol 2015;17:71-77.
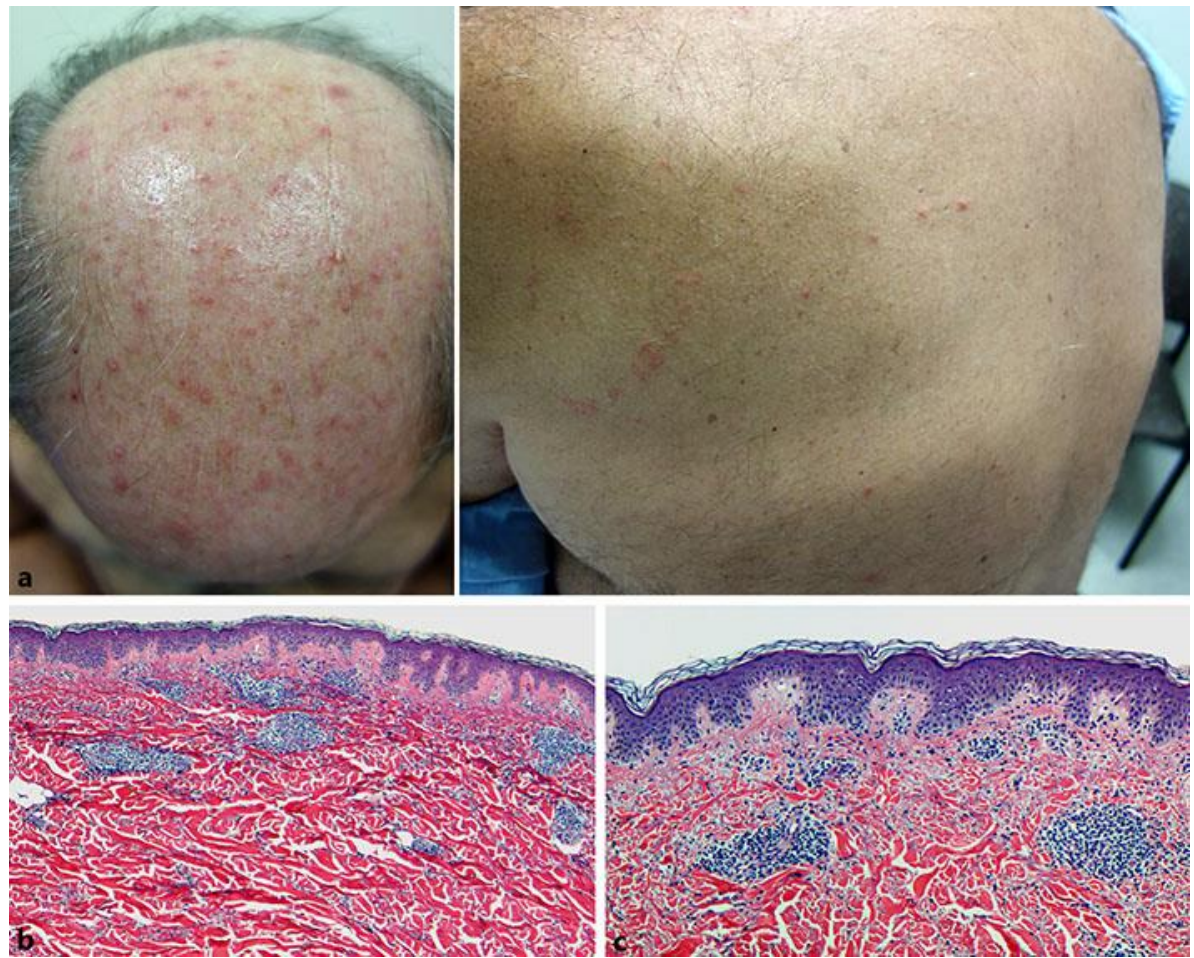

Fig. 1. a Folliculotropic mycosis fungoides of the scalp (left) and left trunk (right). b Superficial perivascular and patchy lichenoid lymphocytic infiltrate is noted with associated epidermotropism. Hematoxylin and eosin. $\times 50$. Upper back. c Lymphocytes show epidermotropism, aligning singly along the basal layer of epidermis. No spongiosis is noted. Hematoxylin and eosin. $\times 100$. Upper back. 